Article

\title{
Evaluation of Satellite Imagery for Monitoring Pacific Walruses at a Large Coastal Haulout
}

\author{
Anthony S. Fischbach ${ }^{1, *(D)}$ and David C. Douglas ${ }^{2}$ (D) \\ 1 U.S. Geological Survey Alaska Science Center, 4210 University Dr., Anchorage, AK 99508, USA \\ 2 U.S. Geological Survey Alaska Science Center, 250 Egan Dr., Juneau, AK 99801, USA; ddouglas@usgs.gov \\ * Correspondence: afischbach@usgs.gov; Tel.: +1-907-786-7145
}

check for updates

Citation: Fischbach, A.S.; Douglas, D.C. Evaluation of Satellite Imagery for Monitoring Pacific Walruses at a Large Coastal Haulout. Remote Sens. 2021, 13, 4266. https://doi.org/ $10.3390 /$ rs13214266

Academic Editors: Barbara Bollard and Lorenzo Fiori

Received: 4 August 2021

Accepted: 18 October 2021

Published: 23 October 2021

Publisher's Note: MDPI stays neutral with regard to jurisdictional claims in published maps and institutional affiliations.

Copyright: (c) 2021 by the authors. Licensee MDPI, Basel, Switzerland. This article is an open access article distributed under the terms and conditions of the Creative Commons Attribution (CC BY) license (https:// creativecommons.org/licenses/by/ $4.0 /)$.
Abstract: Pacific walruses (Odobenus rosmarus divergens) are using coastal haulouts in the Chukchi Sea more often and in larger numbers to rest between foraging bouts in late summer and autumn in recent years, because climate warming has reduced availability of sea ice that historically had provided resting platforms near their preferred benthic feeding grounds. With greater numbers of walruses hauling out in large aggregations, new opportunities are presented for monitoring the population. Here we evaluate different types of satellite imagery for detecting and delineating the peripheries of walrus aggregations at a commonly used haulout near Point Lay, Alaska, in 2018-2020. We evaluated optical and radar imagery ranging in pixel resolutions from $40 \mathrm{~m}$ to $\sim 1 \mathrm{~m}$ : specifically, optical imagery from Landsat, Sentinel-2, Planet Labs, and DigitalGlobe, and synthetic aperture radar (SAR) imagery from Sentinel-1 and TerraSAR-X. Three observers independently examined satellite images to detect walrus aggregations and digitized their peripheries using visual interpretation. We compared interpretations between observers and to high-resolution $(\sim 2 \mathrm{~cm})$ ortho-corrected imagery collected by a small unoccupied aerial system (UAS). Roughly two-thirds of the time, clouds precluded clear optical views of the study area from satellite. SAR was unaffected by clouds (and darkness) and provided unambiguous signatures of walrus aggregations at the Point Lay haulout. Among imagery types with 4-10 m resolution, observers unanimously agreed on all detections of walruses, and attained an average 65\% overlap (sd 12.0, n 100) in their delineations of aggregation boundaries. For imagery with $\sim 1 \mathrm{~m}$ resolution, overlap agreement was higher (mean $85 \%$, sd 3.0, $\mathrm{n} 11$ ). We found that optical satellite sensors with moderate resolution and high revisitation rates, such as PlanetScope and Sentinel-2, demonstrated robust and repeatable qualities for monitoring walrus haulouts, but temporal gaps between observations due to clouds were common. SAR imagery also demonstrated robust capabilities for monitoring the Point Lay haulout, but more research is needed to evaluate SAR at haulouts with more complex local terrain and beach substrates.

Keywords: earth observing; Odobenus rosmarus divergens; synthetic aperture radar; optical; visual interpretation

\section{Introduction}

Pacific walruses (Odobenus rosmarus divergens) haulout on the coast to rest when sea ice is unavailable over continental-shelf waters. When hauled out on land, walruses are at risk from human activities including disturbances that can result in death from stampeding [1] or potentially by contaminants from marine spill events [2]. Mitigating disturbance or pollution risks requires near-real-time information about the presence and relative size of coastal haulouts during ice-free periods. Large aggregations at coastal haulout sites contrast with small, dispersed walrus groups that rest on ice floes when sea ice is present over their offshore feeding grounds [3,4]. Large aggregations at terrestrial haulouts present an opportunity to survey and enumerate walruses with greater precision than may be achieved with offshore surveys [5]. Nevertheless, coastal haulout locations themselves are typically remote and challenging to access, making on-site survey efforts costly and sporadic at best [6]. 
The periods of ice-free conditions during late summer and autumn in the Arctic are lengthening due to warming [7], especially in the Chukchi Sea where Pacific walruses seasonally range. Since 2007, during most years, sea ice has retreated northward beyond the continental shelf in the late summer and autumn, leaving Pacific walruses with no ice on which to rest between foraging bouts. This fundamental change in the distribution of sea ice across the summer and autumn range of Pacific walruses has resulted in larger numbers coming ashore for longer periods on both the U.S. and Russian coasts of the Chukchi Sea [8]. In the U.S., large haulouts have formed on the barrier islands near Point Lay, Alaska [6], in nearly all years since 2007 (except 2008 and 2012), when sea ice retreated beyond the continental shelf.

When walruses haulout on land, they group tightly together in herds that may extend over hundreds or even thousands of meters of shoreline and up to one hundred meters inland. Large walrus aggregations are visually distinct from surrounding coastal features due to their color and texture, even when viewed at great distances or with relatively course resolution imagery. As such, some types of satellite imagery have been used successfully to distinguish walruses. Burn and Cody [9] pioneered detection of walrus haulouts with the use of high-resolution optical imagery from the QuickBird satellite $(0.6 \mathrm{~m}$ panchromatic and $2.4 \mathrm{~m}$ multispectral). They identified walrus groups with as few as two animals and related walrus groups identifiable in the satellite imagery to on-site observer counts. Atlantic walruses on the shores of the Barents Sea were apparent in EROS-B panchromatic $0.7 \mathrm{~m}$ imagery [10], and Pacific walruses were detectable in GeoEye $0.5 \mathrm{~m}$ panchromatic imagery near Wrangel Island, Russia [11]. The Greenland Institute of Natural Resources examined the capability of detecting small walrus groups through statistical processing of high-resolution imagery from Worldview, Pléiades, and SPOT [12]. Despite these successes visualizing walruses with satellite sensors, systematic reconnaissance of haulouts has been hampered by infrequent data collections, cloud cover, timely access, and cost. High-resolution optical satellite imagery has also proved useful for enumerating other pinniped species such as Weddell seals (Leptonychotes weddellii) [13], elephant seals (Mirounga leonina) [14], and gray seals (Halichoerus grypus) [15], and such applications will likely expand as the number of high-resolution satellite systems increases [15]. No study to date has evaluated the repeatability and validity of interpreting walrus haulouts from imagery that spans a breadth of Earth observing satellite sensors that have recently become operational.

Over the past decade, civil access to both optical and SAR imagery increased qualitatively for research and applied purposes. New satellite constellations have increased collection periodicity and improved resolution capability. These constellations support imagery acquired with reduced revisit intervals on the scale of days to hours, moderate $(10$ to $40 \mathrm{~m})$ or high $(0.4 \mathrm{~m}$ to $4 \mathrm{~m})$ image resolutions, and some with active radar instruments that can discriminate ground features through clouds and at night.

Under clear-sky daytime conditions, walrus haulouts can be imaged with several optical sensors operating in the visible to infra-red spectrum. The joint National Aeronautics and Space Administration (NASA) and U.S. Geological Survey (USGS) Landsat program [16] has collected multispectral imagery continuously since 1972. The recently launched Landsat- 8 satellite collects multi-band imagery worldwide every 16 days at the equator with $30 \mathrm{~m}$ resolution. The European Space Agency operates the Sentinel-2 mission [17] with two satellites launched in 2015 and 2017 into complimentary polar orbits that together can collect $10 \mathrm{~m}$ resolution multispectral imagery worldwide every 5 days at the equator. Both Landsat and Sentinel imagery are publicly available without cost. Commercial satellites began collecting very-high resolution ( $1 \mathrm{~m}$ or less) optical images with the launch of IKONOS in 1999. Archives of commercial imagery from IKONOS, Quickbird, WorldView, and GeoEye are available for purchase through Maxar's DigitalGlobe [18]. Several other optical satellite missions collect very-high resolution imagery, for example, Pléiades [19] and SkySat [20]. With prior coordination, opportunities exist to leverage commercial missions to acquire imagery of specific areas at specific times. 
Traditional earth observing satellite missions have relied on customized engineering to build individual satellites and sensors requiring dedicated heavy-lift launch capabilities. In 2003, a new satellite remote sensing paradigm debuted based on deploying a constellation of small satellites built from commercial components and assembled into a standardized form called a CubeSat weighing $\leq 1.3 \mathrm{~kg}$ each $[20,21]$. Their small size allowed CubeSats to be sent into orbit opportunistically with other missions or carried by rockets configured to deploy dozens in a single launch [22]. In 2010, Planet Labs [20] formed to create an earth observing constellation of CubeSats, each with a consumer-grade optical telescope and a 4-band (red, green, blue, and near infra-red) digital sensor. Planet put the first CubeSat into orbit in 2013. By 2018, 140 had become operational in its PlanetScope constellation which is capable of imaging the Earth's entire landmass at $4 \mathrm{~m}$ resolution every day [23,24].

Optical ground imaging in Arctic coastal areas during the walrus haulout season is often impossible due to persistent clouds, fog, and the rapid loss of daylight in autumn. However, active radar instruments can acquire unobscured day/night images of walrus haulouts because the wavelengths are unaffected by atmospheric water-vapor or darkness. In April 2014, the European Space Agency launched the Sentinel-1 mission to collect C-band synthetic aperture radar (SAR) imagery of the Earth's land masses in dual polarization imaging modes, processed to $10-\mathrm{m}$ resolution and available to the public in near-realtime [17]. Several other SAR data archives and acquisition capabilities exist (see Section 4), but none maintain free, near-real-time global archives like Sentinel-1.

In this study, we evaluate the repeatability of interpreting the occurrence, aerial extent, and location of walrus haulouts from a representative sampling of available Earth observing satellite imagery. We acquired data from a variety of satellite imagery sources (public and commercial) to evaluate their effectiveness in revealing walrus aggregations at the Point Lay haulout. We recognize that our comparisons do not include all possible satellite missions, rather we selected a representative subset of optical and SAR missions that span a range of spatial and temporal resolutions. To inform the validity of our imagery interpretations, we utilized very high-resolution imagery $(\sim 2 \mathrm{~cm})$ that was collected at the Point Lay haulout during the late summers of 2018 and 2019 using a small unoccupied aerial system (UAS) [25]. Because none of the Earth observing satellite imagery available to this study enabled the counting of walruses when gathered closely together in a haulout, and because walrus density varies substantially at coastal haulouts, we did not seek to estimate abundance [25]. Prior to initiating the study, we consulted with the Eskimo Walrus Commission [26], an Alaska Native co-management group that represents coastal communities with cultures that rely on walruses, to ensure that our methods would not adversely affect conservation efforts nor infringe on the privacy of local residents.

\section{Materials and Methods}

\subsection{UAS Imagery}

During 2018 and 2019, fine-scale UAS aerial imagery was collected [25] as part of a walrus abundance estimation study. The aerial images ( $\sim \mathrm{cm}$ resolution) were processed into orthoimages and the outlines of walrus aggregations resting on shore were digitized as geospatial polygons in a desktop GIS at a scale of 1:400, and full details of the UAS imagery collection, processing and interpretation are available within the metadata record of the data release [25]. UAS surveys were only flown when daylight and weather permitted (less than 15 knot winds and no precipitation). In total, 27 UAS surveys were completed, 13 in 2018 and 14 in 2019, including an unpublished survey of the beach without walruses present on 27 August 2019 (Alaska time; USGS unpublished data) with up to 2 surveys flown per day, which resulted in 8 flight days in 2018 and 9 in 2019.

\subsection{Satellite Imagery}

In Spring 2020, we systematically queried archives of GeoEye-1, LandSat-8, PlanetScope, Sentinel-2, and WorldView for imagery of the Point Lay haulout area, spanning roughly $9 \mathrm{~km}$ of barrier island beach (bounding geographic coordinates: $162.7^{\circ} \mathrm{W}, 69.6^{\circ} \mathrm{N}$, 
$163.4^{\circ} \mathrm{W}$, and $69.9^{\circ} \mathrm{N}$ ) during $25 \mathrm{July}-15$ November 2018 and 2019 and obtained all available imagery. We also systematically queried the ground range detected SAR imagery archive of Sentinel-1 C-band $10 \mathrm{~m}$ resolution VH cross-polarization IW (interferometric wide) and the $40 \mathrm{~m}$ resolution HV cross-polarization EW (extra wide) swath modes. We arranged with the TerraSAR-X mission to collect X-band SAR imagery of Point Lay during the 2020 walrus haulout season, after preliminary exploration of the Sentinel-1 SAR imagery indicated the operational value of SAR for haulout monitoring. For this purpose, TerraSAR-X representatives recommended the instrument's highest resolution image mode ("staring spotlight", abbreviated as TerrSAR-X ss in figure legends) with $\sim 1.1 \mathrm{~m}$ resolution in a single polarization, or the "stripmap" (abbreviated as TerrSAR-X sm in figure legends) mode with $\sim 3.5 \mathrm{~m}$ resolution and a more extensive swath width [27]. TerraSAR-X delivered multi-look ground range detected SAR imagery processed with a radiometrically enhanced mode to reduce speckle and science-grade orbital parameters to optimize geographic registration. We then obtained all available imagery from the Sentinel-1, Sentinel-2, and LandSat-8 public archives during the 2020 study season to compliment the TerraSAR-X imagery. We also examined browse imagery in the Planet 2020 archive to assess the frequency of clear sky conditions, however we did not purchase 2020 PlanetScope imagery for analysis. Use of Google Earth Engine [28] enabled efficient access to Sentinel and Landsat imagery.

\subsection{Visual Interpretation}

To recognize and delineate walrus aggregations on shore, we first examined each imagery type before walruses arrived to orient ourselves with how the study area's coastal landscape was depicted in the respective imagery, including how to recognize local features throughout the area such as variations in beach width, banks at the edge of the storm high-tide line, upland vegetation, and remnants of a nearby historic settlement and military infrastructure. We augmented our orientation to local features in the study area with publicly available commercial satellite imagery composites [29] and maps that indicated locations of historic buildings [30]. Walruses disturb beaches and upland vegetation when they gather in large numbers, churning up the soil and defecating. Occupied haulout areas become discolored by these behaviors. Because the discoloration lingers after walruses leave, we examined images in chronological order to more reliably recognize areas that had recently been occupied or vacated. We visualized the Landsat, PlanetScope, and Sentinel-2 multispectral image bands as standard true-color red-green-blue (RGB) images, as well as false-color composites using the near infra-red, red, and green bands for the RGB channels respectively. We also examined the near infrared band individually. We visualized panchromatic imagery from GeoEye-1 and WorldView as single band images. We displayed WorldView multispectral images as RGB false color composites using the near IR2, near IR1, and red edge bands, respectively. For display, we stretched each band's color ramp from the 2 nd to the 98 th percentile of pixel values within the study area, and if useful, we adjusted brightness and contrast settings to optimize visual discrimination among landscape features. If thin clouds were partially present over the study area, we applied image enhancement methods separately to areas with and without clouds. We classified images as "clear view" if features over the entire haulout area could be readily observed, including the near-IR band if it effectively penetrated thin clouds that had contaminated the visible bands. We made no attempt to detect walruses in optical imagery that lacked clear views (i.e., cloudy images). Each satellite mission collected no more than one image per day, except for PlanetScope which sometimes acquired two or three images from different satellites. For calculations of clear view revisit rates, we only considered the PlanetScope clear view acquisition time collected closest to solar noon for any given day.

We recognized walrus aggregations in the true-color imagery by a distinctive redbrown coloration along the ocean-facing beach that contrasted with the adjacent brown beach, green upland vegetation, and dark brown trampled upland vegetation (or sometimes white fresh snow). Walruses in the false-color image composites were recognizable by similar patterns but with different contrasting colorations. We recognized walrus aggre- 
gations in the near infra-red band by distinctive mid-level intensity values that contrasted with darker levels of the adjacent beach, variable levels of the adjacent uplands, and brighter levels in the nearshore surf zone. We detected walruses in the Sentinel-1 crosspolarization normalized backscatter $(\sigma 0$, sigma nought) imagery when displayed as a single band stretched from -25 to $0 \mathrm{~dB}$. We displayed the TerraSAR-X staring spotlight (single polarization) $\sigma 0$ images by stretching values from 1 to 512 . We displayed the TerrSAR-X stripmap dual-polarized imagery as a false color RGB image with VV assigned to red, VH assigned to blue (each stretched from 75 to 250), and we left green empty. We recognized walrus aggregations as large contiguous clusters of pixels with high radar backscatter on the ocean-facing side of the barrier island that contrasted distinctly with the surrounding coastal landscape.

Three observers, experienced in airborne walrus reconnaissance (and the authors of the data release [31]), independently interpreted each satellite image. Each observer digitized the periphery of apparent walrus aggregations when comprised of at least 6 contiguous pixels. Walrus aggregations were digitized while using a desktop GIS to display the imagery in a UTM Zone-3 projection at a 1:10,000 scale for imagery with pixel sizes $\geq 10 \mathrm{~m}$, at 1:5000 scale for imagery with pixel sizes $3-9 \mathrm{~m}$, and at a 1:2000 scale for imagery with resolutions $<3 \mathrm{~m}$.

\subsection{Analysis}

We quantified variability between observers for each imagery type in terms of (1) consensus in recognizing which satellite images contained detectable walruses, (2) agreement on the digitized areal extent, and (3) spatial agreement on the digitized peripheries. Based on the area digitized by each observer for all images with detected walruses, we calculated the root mean square error (RMSE) among observer pairs, then divided the RMSE by the observer average to attain a CV (coefficient of variation) RMSE. We averaged CV-RMSE by imagery type to evaluate how image resolution influenced disagreement among observers. We also quantified spatial agreement among the observers for each image by ratioing the area of 3-way geographic intersection among the digitized aggregations to the area of the corresponding 3-way geographic union. We averaged this ratio (the area of the geographic union against the area of the geographic intersection) for each imagery type, plotted it, and derived the linear regression slope forced through zero (and r-square) to compare, among imagery types, the degree of 3-way spatial observer agreement. The linear regression relies on the interpretation of each image independently by the three observers. Higher slopes indicated greater 3-way agreement, and higher r-squares indicated a greater consistency over the range of different aggregation areas.

We compared satellite image and UAS imagery interpretations collected within $24 \mathrm{~h}$ of one another and assumed that the UAS surveys provided the most accurate delineation of an aggregation's periphery. When satellite imagery was collected within $24 \mathrm{~h}$ of a UAS survey, we compared the area occupied by walrus aggregations identified in the satellite images with that observed in UAS imagery. For each pair of satellite and UAS images, we calculated the percent deviation in the area occupied by walruses as determined in the satellite imagery (the 3-observer average) compared to that determined from the UAS image ((Satellite-UAS)/UAS*100).

\section{Results}

We examined a total of 562 satellite images collected over our study area during 25 July-15 November 2018, 2019, and 2020 [31], among which 207 images had clear views (all 80 SAR images and 127 of the 482 optical images). Of the 207 clear view images, we obtained full-resolution digital data for 195 (DigitalGlobe $=3$, LandSat-8 = 11, PlanetScope $=54$, Sentinel-1 EW = 18, Sentinel-1 IW = 46, Sentinel-2 = 47, TerraSAR-X staring spotlight $=12$, and TerraSAR-X stripmap $=4$ ).

Examples of each imagery type when walruses were present are shown in Figure 1. Most of the clear view optical images were obtained by PlanetScope and Sentinel-2. Al- 
though both of these missions collected imagery every 1-2 days over the study area, the median clear view revisit rate for each mission was 3 days (Table 1), and with considerable variability (PlanetScope IQR, 4.7 day and Sentinel-2 IQR, 5.0 day) resulting in an irregular time series for both imagery types. Few clear view images were collected by the Landsat- 8 mission due to the long 16-day revisit time and variable cloud conditions. During the 2020 haulout season PlanetScope browse images documented only 12 clear view days. Although we had not prearranged for image collections by DigitalGlobe, three clear view images were available in the archives: one each from GeoEye-1, WorldView-1, and WorldView-2. Regardless of the mission, no optical images were available after October 23, presumably because solar illumination failed to meet data collection or processing thresholds.

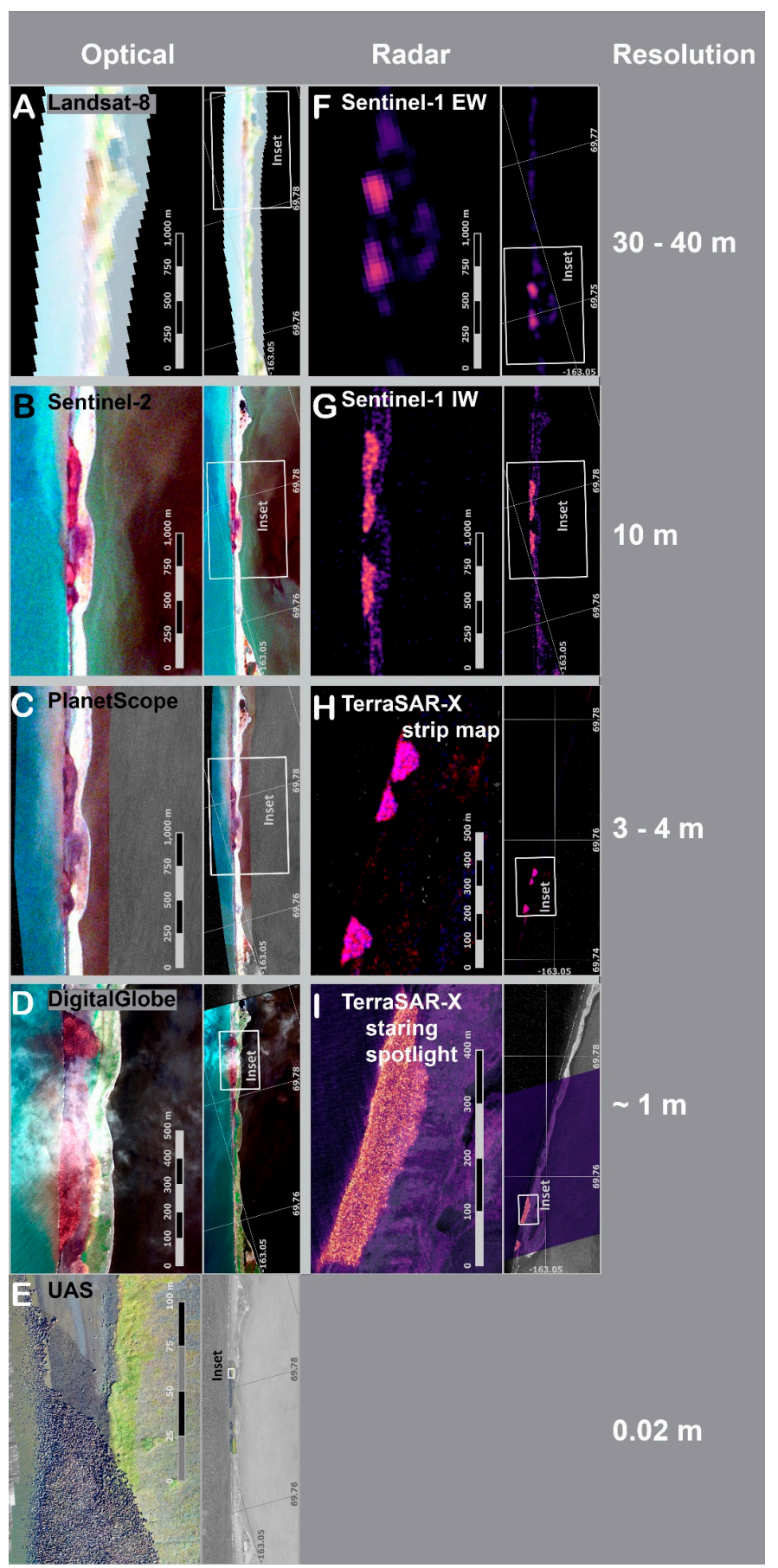

Figure 1. Examples of the imagery types evaluated in this study for detecting Pacific walrus haulout aggregations on the beach near Point Lay Alaska. Each panel is labeled with the name of the imagery 
type that is used in subsequent figure legends. Each panel has an inset locator map on the right that includes a latitude/longitude graticule to enable precise geographic location of the walrus aggregations. The left column includes optical imagery types displayed with a true-color RGB enhancement (red, green, and blue bands): (A) Landsat-8 (30 m resolution, 2019-08-17 22:31Z), (B) Sentinel-2 (10 m, 2018-09-07 23:05Z), (C) PlanetScope (4 m, 2018-09-07 22:08Z, ( PlanetLabs), (D) WorldView-2 (1.5 m, 2019-08-11 22:57Z, ( ) DigitalGlobe), and (E) unoccupied aerial system (UAS) imagery (2 cm, 2018-09-07 20:49Z, included for comparison with satellite imagery). The right column displays SAR images of normalized backscatter (sigma nought): (F) Sentinel-1 EW with VV polarization (40 m, 2020-09-15 17:39Z), (G) Sentinel-1 IW with HV polarization (10 m, 2018-09-08 17:41Z), (H) TerraSAR-X stripmap dual polarization (3.5 m, 2020-09-17 04:19Z, (C DLR 2020), and (I) TeraSAR-X staring spotlight with VV polarization (1.4 m, 2020-09-18 04:02Z, C DLR 2020). SAR images " $F$ ", " $G$ ", and "I" display sigma nought across a pseudo-color ramp ranging from dark purple to light yellow, while image " $\mathrm{H}$ " is displayed as RGB pseudo-color with red $=\mathrm{HH}$ polarization, green $=$ null, and blue $=\mathrm{HV}$ polarization .

Archived Sentinel-1 SAR images of the study area were available during 2018, 2019 and 2020 in both the IW $(n=46)$ and the EW $(n=18)$ imaging modes [31]. Limited daylight in November did not impede the collection of Sentinel-1 imagery. Sentinel-1 IW images were available for Point Lay every 12 days in 2018 (collected by Sentinel-1A only), and in 2019 and 2020 (with collections by both Sentinel-1A and Sentinel-1B) with a revisit rate of roughly 10 days. Sentinel-1 EW images were only available in 2019 and 2020, with mostly a 12-day revisit interval, but occasionally a 4 or 8 day. For TerraSAR-X, we obtained data from two imaging modes, staring spotlight $(n=12)$ and dual-polarized stripmap $(n=4)$.

Pooling the walrus detections across all image types conveyed information about the seasonal timing and within-season dynamics of occupancy at the Point Lay haulout (Figure 2). During the three study years, we could estimate the start and end dates of the walrus haulout season based on the first and last detections of walrus aggregations: 26 August-16 October 2018, 10 August-21 October 2019, and 2 August-4 October 2020. Periods of persistent cloudiness introduced temporal gaps into the haulout area estimates from optical imagery, but those gaps would often be filled with estimates from SAR imagery.

Excluding data from the coarse Sentinel-1 EW images, we detected walrus aggregations that ranged in size from 0.14 to 11 ha. The vertical bars in Figure 2 represent the full range of areas occupied by walruses, as delineated by the three observers. Variability among the observer interpretations was typically small relative to the mean area occupied across all imagery types, except for those from the coarse Sentinel-1 EW. The area occupied by walruses, as interpreted from satellite imagery, qualitatively agreed with the UAS surveys (Figure 2). The magnitude of day-to-day fluctuations in the area occupied, as documented by UAS surveys, emulated estimates obtained from satellite imagery. The size of the area occupied varied from zero to as much as eight or more hectares in each study year (Figure 2), excluding the Sentinel-1 EW estimates. Reasonable agreement between satellite imagery types was often evident when images were collected within a day of one another (again, disregarding the Sentinel-1 EW estimates). 

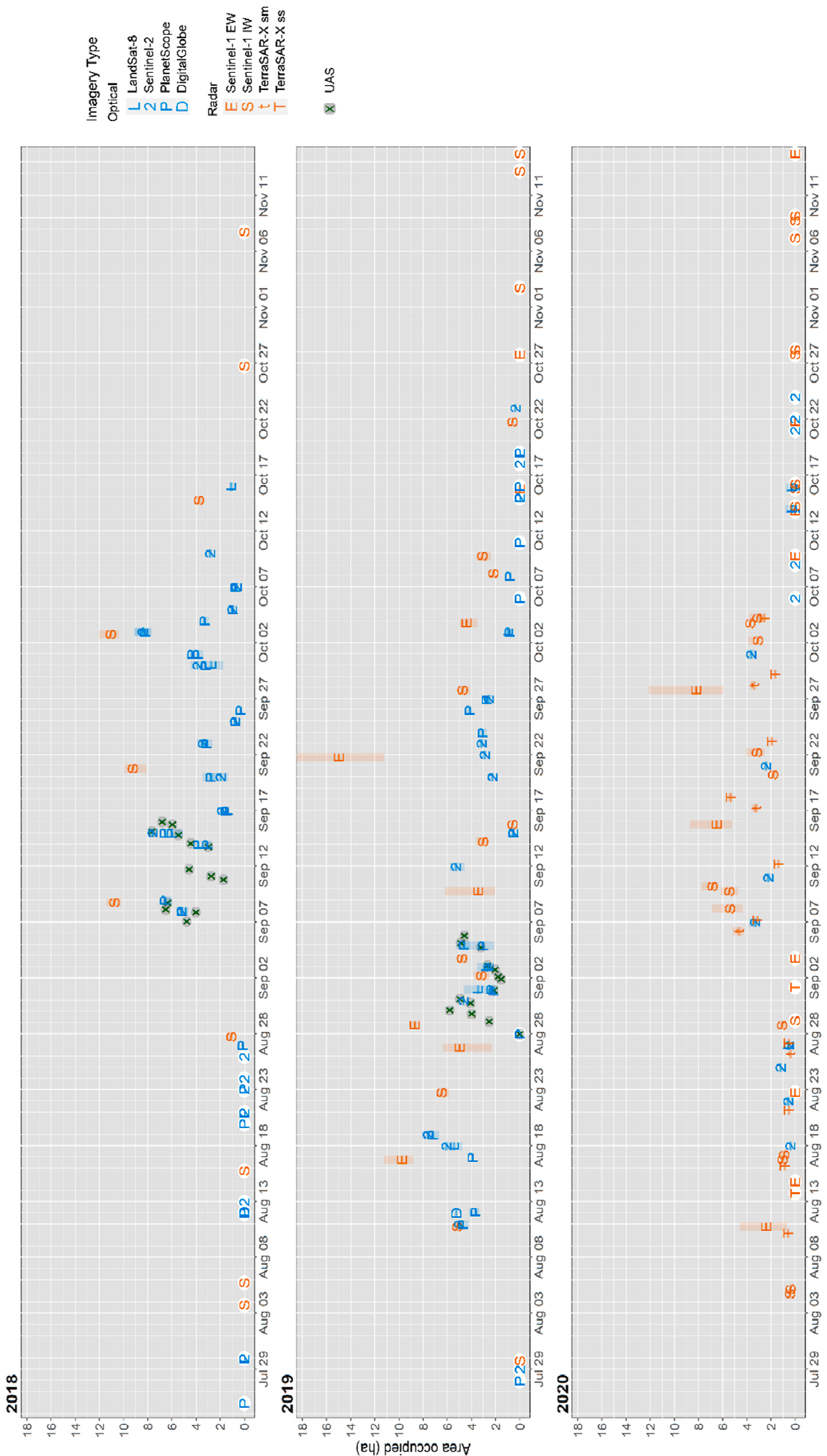

Figure 2. Size of the area occupied by walrus aggregations hauled out at Point Lay Alaska during 25 July-15 November 2018, 2019, and 2020 interpreted from various imagery types. Colored symbols indicate the mean estimated area among the three observers and shaded vertical bars indicate the full range of estimates. Symbol color denotes optical (blue) or SAR (red) imagery. The size of areas interpreted from UAS surveys are displayed as gray dots with an embedded " $X$ ". Images interpreted to have no walruses present are plotted with a white circular background to distinguish them from images with a small area of walruses. 
Eighteen satellite images were collected within $24 \mathrm{~h}$ of a UAS survey, and because UAS surveys were often conducted in both the morning and afternoon of the same or consecutive days, 26 UAS surveys were collected within $24 \mathrm{~h}$ of another UAS survey (Figure 3). All walrus aggregations apparent in the satellite images were also present at similar locales in the matched UAS imagery, and vice-versa. However, we found substantial differences in walrus aggregation size, even between pairs of UAS images collected $<9 \mathrm{~h}$ apart, revealing just how dynamic the walrus aggregations can be over short time intervals. UAS surveys of walrus aggregations collected within 5-9 h of another UAS survey documented proportional changes in the area occupied by as much as $50 \%$ (Figure 3). That magnitude of deviation between paired UAS surveys was evident and somewhat greater when survey times differed by $12-24 \mathrm{~h}$. Notably among the optical satellite imagery types, the range of deviations between the satellite-derived and UAS-derived estimates followed the same pattern as that between the UAS surveys themselves, indicating that the former deviations (those between optical satellite and UAS imagery) could be entirely due to the dynamics of walruses shifting on and off the haulout and/or shifts in haulout density during the relatively short intervening time between data collections.

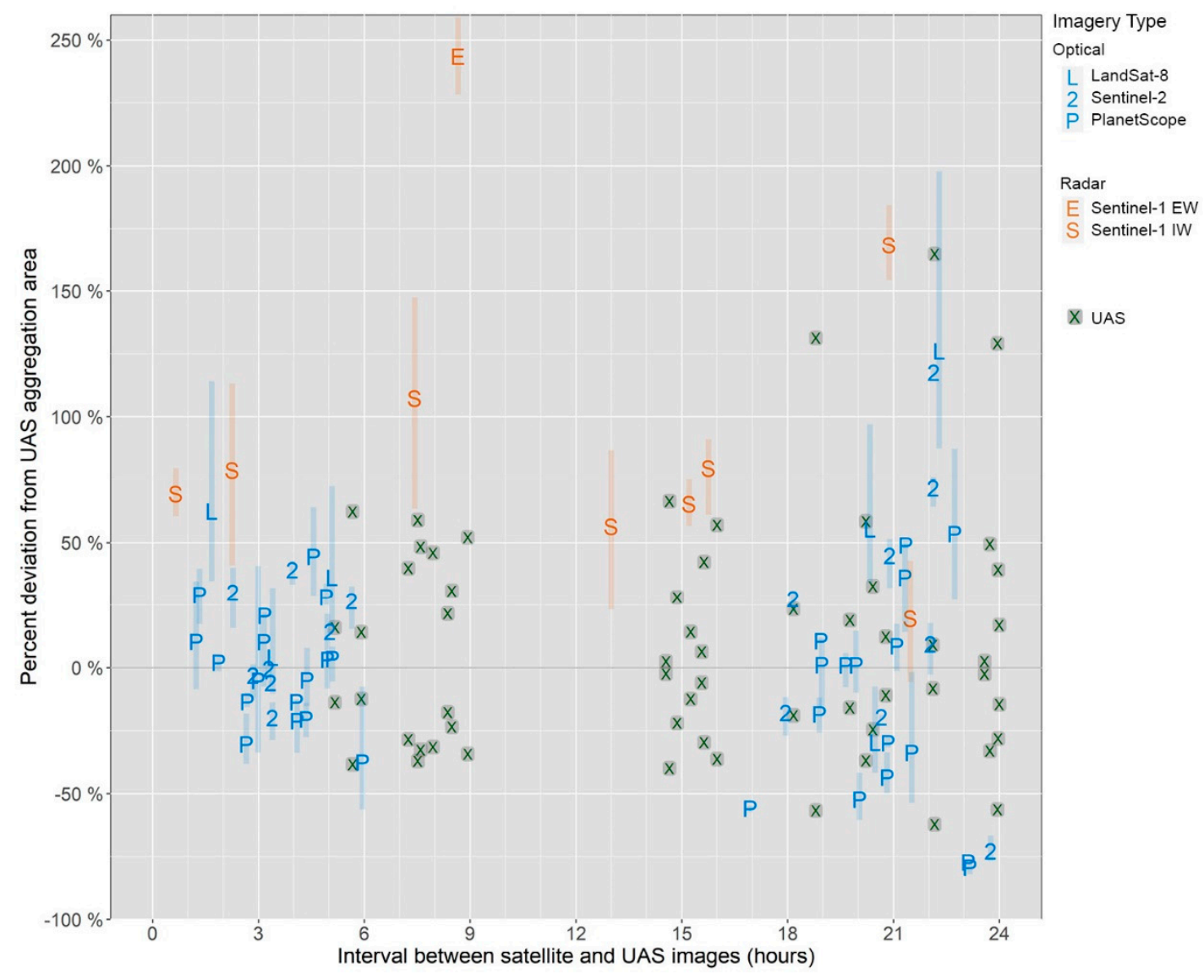

Figure 3. Deviation (percent) between satellite-derived areas of walrus occupancy and those obtained from matched UAS surveys, plotted on the amount of elapsed time between the two surveys (symbols, as in Figure 2). For each satellite image collected within $24 \mathrm{~h}$ of a UAS survey, the percent deviation was calculated as the area estimated from satellite imagery minus the area derived from the paired UAS survey, divided by the UAS survey area. Colored symbols indicate the mean percent deviation among the three observers and shaded vertical bars signify the full range of deviations. For comparison, the same deviations are plotted for UAS surveys matched to other UAS surveys (gray Xs). The plotted data are available as online Supplementary Materials.

Four SAR images were collected within $24 \mathrm{~h}$ of a UAS survey (three Sentinel-1 IW images matched to 8 UAS surveys, and one Sentinel-1 EW image matched to a single UAS survey), and all produced mean area estimates of walrus occupancy that exceeded 
the estimates from paired UAS images. The three Sentinel-1 IW images matched to UAS surveys on the same day $(<8 \mathrm{~h})$ had deviations ranging from $69 \%$ to $107 \%$, and a single same-day Sentinel-1 EW image produced a deviation exceeding $240 \%$.

Observers were unanimous in classifying whether each clear view satellite image $(\mathrm{n}=195)$ had detectable walruses present $(\mathrm{n}=129)$, with the exception of two Landsat-8 images (2020-10-13 22:38Z and 2020-10-15 20:00Z) in which only one observer identified walruses on shore. The digitized extent of aggregations varied among observers, and that variability differed substantially between the satellite missions and imaging modes, as evidenced by the increase in between-observer CV-RMSE that accompanied increasing image resolution (Table 1). Not surprisingly, the average CV-RMSE of the estimated area occupied by walruses was small for the higher resolution imagery (TerraSAR-X staring spotlight and DigitalGlobe), and large for the low-resolution imagery (Sentinel-1 EW and Landsat-8). Observer differences in aggregation size exceeded $50 \%$ of the mean size for coarse-resolution imagery types, $\sim 20 \%$ of the mean for moderate-resolution types, and $\sim 10 \%$ or less among the higher resolution types (Table 1 ).

Table 1. Summary of sample sizes, clear-view revisit rates, and observer variations in detecting and delineating walrus aggregations using different types of satellite imagery. Image sample sizes are provided for the total number of archived images, number with a clear view of the study area, and number with walruses detected. Revisit intervals were calculated using only clear-view images, and one per day for PlanetScope. Sample sizes for the average CV-RMSE, average overlap, and regression slope were the number of images with detected walruses pooled across years. All linear regression slopes were statistically significant $(P<0.0001)$ except for Landsat-8 $(\mathrm{P}>0.05)$.

\begin{tabular}{|c|c|c|c|c|}
\hline $\begin{array}{l}\text { Satellite Sensor/Type } \\
\text { (Image Resolution) }\end{array}$ & $\begin{array}{c}\text { Image Sample Sizes } \\
\text { Year: } \\
\text { Archive/Clear/Walrus }\end{array}$ & $\begin{array}{c}\text { Median Days between } \\
\text { Clear-View Image } \\
\text { Revisits (IQR) }\end{array}$ & $\begin{array}{l}\text { Average Observer } \\
\text { CV-RMSE (sd) }\end{array}$ & $\begin{array}{c}\text { Average 3-Way Observer } \\
\text { Overlap Ratio (sd)/ } \\
\text { Regression Slope }\left(\mathbf{R}^{2}\right)\end{array}$ \\
\hline $\begin{array}{l}\text { Sentinel-1 EW/SAR } \\
\qquad(40 \mathrm{~m})\end{array}$ & $\begin{array}{c}\text { 2018: NA } \\
\text { 2019: } 8 / 8 / 6 \\
\text { 2020: } 10 / 10 / 3\end{array}$ & $12.0(4.0)$ & $0.52(0.37)$ & $\begin{array}{l}0.43(0.16) / \\
0.51(0.964)\end{array}$ \\
\hline $\begin{array}{l}\text { Landsat-8/Optical } \\
\qquad(30 \mathrm{~m})\end{array}$ & $\begin{array}{l}\text { 2018: } 11 / 3 / 2 \\
\text { 2019: } 13 / 5 / 4 \\
\text { 2020: } 15 / 3 / 3\end{array}$ & $16.0(23.5)$ & $0.78(0.95)$ & $\begin{array}{l}0.23(0.24) / \\
0.20(0.364)\end{array}$ \\
\hline $\begin{array}{l}\text { Sentinel-1 IW/SAR } \\
\qquad(10 \mathrm{~m})\end{array}$ & $\begin{array}{l}\text { 2018: } 10 / 10 / 5 \\
\text { 2019: } 14 / 14 / 10 \\
\text { 2020: } 22 / 22 / 13\end{array}$ & $10.5(10.0)^{1}$ & $0.23(0.11)$ & $\begin{array}{l}0.67(0.10) / \\
0.74(0.990)\end{array}$ \\
\hline $\begin{array}{l}\text { Sentinel-2/Optical } \\
\qquad(10 \mathrm{~m})\end{array}$ & $\begin{array}{c}\text { 2018: } 54 / 17 / 11 \\
\text { 2019: } 52 / 15 / 12 \\
\text { 2020: } 55 / 15 / 8\end{array}$ & $3.0(5.0)$ & $0.21(0.16)$ & $\begin{array}{l}0.64(0.14) / \\
0.73(0.986)\end{array}$ \\
\hline $\begin{array}{l}\text { PlanetScope/Optical } \\
\qquad(3.9 \mathrm{~m})\end{array}$ & $\begin{array}{c}\text { 2018: } 134 / 32 / 23 \\
\text { 2019: } 53 / 22 / 14 \\
\text { 2020: } 92 / 12 / \mathrm{NA}^{2}\end{array}$ & $3.0(4.7)$ & $0.16(0.12)$ & $\begin{array}{l}0.63(0.10) / \\
0.68(0.982)\end{array}$ \\
\hline $\begin{array}{c}\text { TerraSAR-X stripmap/SAR } \\
(3.5 \mathrm{~m})\end{array}$ & 2020: NA/4/4 & $\mathrm{NA}^{3}$ & $0.11(0.04)$ & $\begin{array}{l}0.75(0.059) / \\
0.78(0.999)\end{array}$ \\
\hline $\begin{array}{l}\text { TerraSAR-X staring spotlight/SAR } \\
(1.1 \mathrm{~m})\end{array}$ & 2020: NA/12/10 & $\mathrm{NA}^{3}$ & $0.08(0.03)$ & $\begin{array}{l}0.85(0.032) / \\
0.86(0.999)\end{array}$ \\
\hline $\begin{array}{l}\text { Maxar DigitalGlobe/Optical } \\
\qquad(<1 \mathrm{~m})\end{array}$ & $\begin{array}{c}\text { 2018: } 2 / 2 / 0 \\
\text { 2019: } 1 / 1 / 1 \\
\text { 2020: } 1 / 1 / \mathrm{NA}^{2}\end{array}$ & & 0.04 (NA) & $\begin{array}{l}0.85 \text { (NA)/ } \\
\text { NA (NA) }\end{array}$ \\
\hline
\end{tabular}

\footnotetext{
${ }^{1}$ Archive and clear-view samples sizes are equivalent for Sentinel-1 because SAR is all-weather. ${ }^{2}$ This study did not acquire full resolution PlanetSccope nor DigitalGlobe images from 2020, so no images were evaluated for walrus presence during the 2020 study year. ${ }^{3}$ TerraSAR-X images were prearranged acquisitions, not archive retrievals.
}

Not only did observers differ in estimating the area occupied by walruses, but they also differed in precisely where they delineated the aggregation boundaries. The digitized area of overlap (intersection) common to all three observers, expressed as a fraction of the total (union) area, ranged from 0.25 to 0.85 and was inversely related to image resolution (Table 1). Higher-resolution imagery types, such as TerraSAR-X and DigitalGlobe, more consistently approached a 1-to-1 intersection:union relationship (i.e., perfect 3-way spatial agreement) between observers (Figure 4). For any given imagery type, the degree of spatial consistency achieved among the observers is reflected in how closely the intersection:union 
values adhere to the 1:1 reference line displayed in Figure 4, and by the regression slopes presented in Table 1. Lower-resolution imagery types (Landsat and Sentinel-1 EW) had the greatest spatial disparity among observer delineations of aggregations. In fact, some Landsat images produced complete or near-complete disparity in the locations (or even presence) of walruses, and overall had the lowest spatial correspondence among observers. Although the Sentinel-1 EW images had coarser resolution $(40 \mathrm{~m})$, observers were unanimous in identifying images with walruses and had slightly better spatial agreement than Landsat in delineating the aggregations. Among the moderate resolution image types (PlanetScope, Sentinel-2, Sentinel-1 IW, and TerraSAR-X stripmap), the spatial agreement among observers was markedly better, with regression slopes ranging between $0.68-0.78$. As expected, observers attained the highest levels of 3-way spatial agreement when delineating walrus aggregations with the $\sim 1$-m-resolution TerraSAR-X staring spotlight, which resulted in an intersection:union slope of 0.85 , and with DigitalGlobe, which had an average observer overlap of 0.85 for the one clear view image we obtained with walruses present (Table 1).

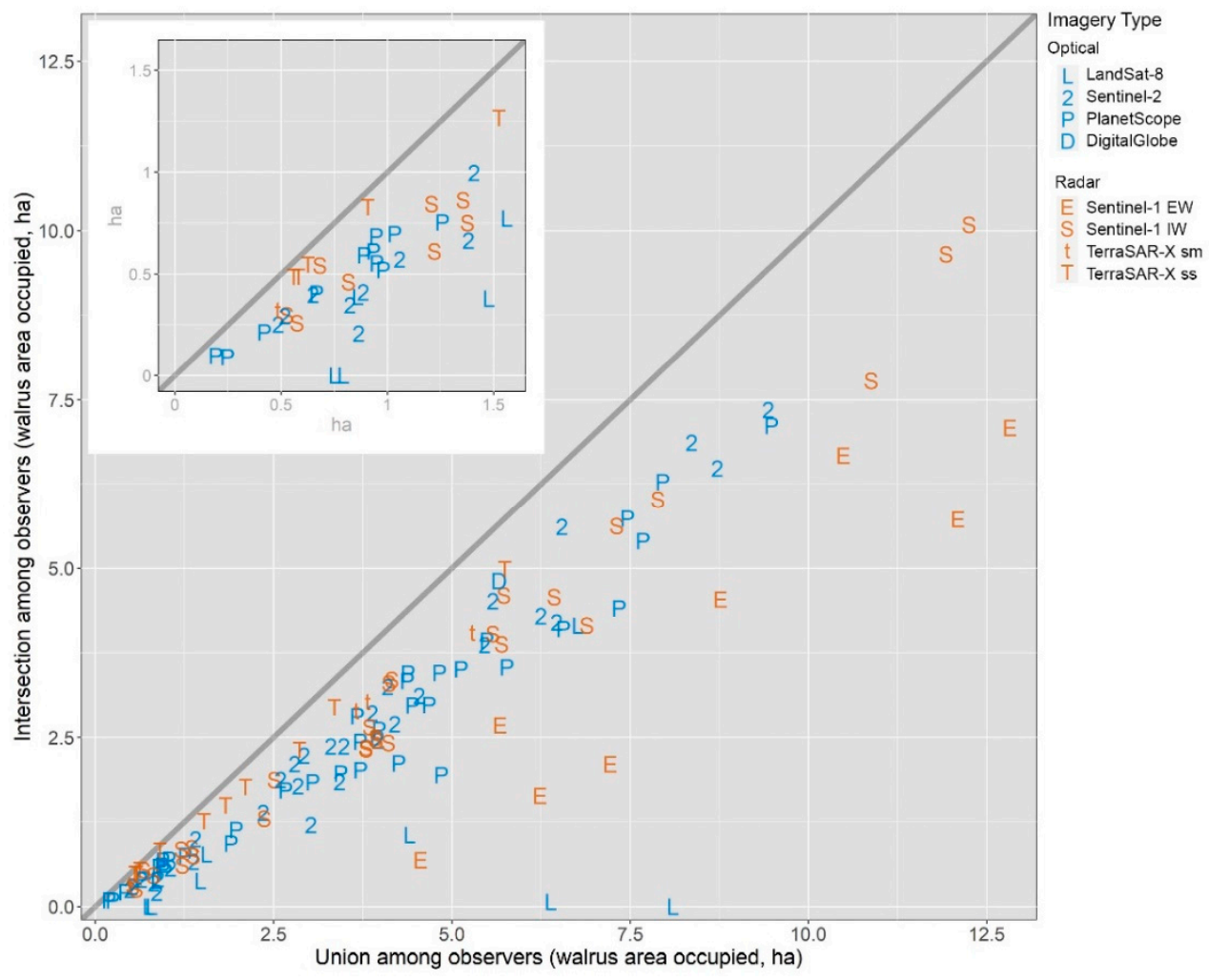

Figure 4. Variation among observers in determining both the location and size of walruses from satellite images. The area of 3-way intersection among the observers' delineations of walrus aggregations in each satellite image ( $y$ axis) are plotted on the area of the geographic union of the observers' delineations. A perfect 3-way spatial agreement would attain a 1:1 ratio. Symbols: as in Figure 2. Linear regression slopes for each imagery type are displayed in Table 1. One Sentinel-1 EW outlier was excluded from this graph: $\mathrm{x}=20.11, \mathrm{y}=10.75$ ).

\section{Discussion}

We found that publicly and commercially available satellite imagery can be used to detect the presence, areal size, and geographic position of walrus aggregations at a terrestrial haulout near Point Lay, Alaska. Not only were observers able to consistently determine when walruses were present, they also were able to delineate the extent of aggregations with considerable agreement and consistency with aerial surveys. These findings suggest that satellite reconnaissance may provide a tool for monitoring walrus haulout occupancy and dynamics, as may be required by resource managers. Both the 
reliability and precision of detecting walruses with satellite imagery are important criteria for monitoring, and both varied among the different types of imagery we evaluated. For optical imaging, reliability was limited by (1) the mission's revisitation frequency, a predictable factor (i.e., a factor that may be predicted at the start of a study), (2) adequate solar illumination, a predictable factor, and (3) clear-sky conditions, an unpredictable factor. For SAR imaging, reliability was limited by (1) the mission's revisitation frequency and (2) mission-controlled acquisition scheduling. Below, we discuss technical advantages and disadvantages of the different imagery types for monitoring walrus haulouts. Monitoring efforts can achieve increased temporal resolution by combining interpreted data from various imagery types, as evidenced by the temporal resolution of the haulout occupancy across the three study seasons (Figure 2). However, we do not attempt cost assessments of commercial imagery because pricing can vary widely, depending on factors like volume, latency, institutional licensing, and contractual arrangements.

Coastal walrus haulout sizes can change substantially over short time intervals. During less than five hours, [32] reported a $46 \%$ reduction in the number of walruses hauled out at Point Lay. During the 2018 and 2019 UAS surveys, fluctuations of up to $60 \%$ in the area occupied were documented between UAS surveys collected 5 to $9 \mathrm{~h}$ apart (Figure 3, [25]). These fluctuations were not only due to changes in the peripheral extent of walrus aggregations on shore, but also due to the formation of holes within aggregations which may not be evident in some satellite imagery, depending on resolution. Among UAS surveys conducted within $9 \mathrm{~h}$ of a prior survey $(\mathrm{n}=10)$, the estimated number of walrus individuals ranged from 1900 to 14,780 [25]. Such dynamics over the course of only a few hours confounded our attempts to directly compare haulout area estimates from satellite and UAS imagery because most were not collected near-coincidently (on the order of minutes, not hours).

\subsection{Optical Imagery}

Clouds were the most prevalent obstacle for detecting walruses with optical imagery at the Point Lay haulout during the haulout season. Although aggregations could sometimes be delineated through thin clouds using a near-infrared band, opaque cloud cover was common and often persistent. Even the PlanetScope constellation with near-daily revisitations was precluded from collecting clear view imagery for periods lasting upwards of ten days during each year. Cloud cover varied across the study years, but it is reasonable to expect that on-average roughly two-thirds of optical images at Point Lay could be contaminated by clouds, resulting in data gaps of variable duration (Table 1 and Figure 2). The Sentinel-2 and PlanetScope time series, taken together, had gaps lasting $>10$ days in both 2019 and 2020, and 2 such gaps in 2018. Periods of persistent clouds were also reflected in a 2005-2020 record of weather station data from the nearby Point Lay airport [33]. Annually during 25 July to 23 October, at times suitable for optical remote sensing (10:00-16:00 local), the fraction of hourly sky-condition records classified as being 'clear' or with 'few clouds' averaged $35 \%$ (sd 13\%, n 14 years), consistent with the roughly two-thirds fraction of cloud-contaminated satellite images that we had obtained for 2018-2020.

Nighttime also prevents use of optical imagery for detecting walruses, a limitation that rapidly establishes during autumn at high latitudes. For example, at Point Lay's latitude $\left(\sim 69.7^{\circ} \mathrm{N}\right)$ in mid-October, the maximum sun elevation is $\sim 12^{\circ}$, and by late-October it drops to $<6^{\circ}$ [34]. No Sentinel-2 or PlanetScope images of Point Lay were available in the archives after $\sim 23$ October, presumably due to insufficient solar illumination. Although walruses appeared to have vacated the haulout by mid-October during the years of our study (Figure 2), haulouts on the northern Russian coast of Chukotka are commonly used throughout November, including the largest known haulout at Cape Serdtse Kamen' [35], so objectives to monitor haulouts range-wide with optical sensors would face late-autumn limitations.

Given previously published accounts of detecting walruses with $\sim 1$-m resolution satellite imagery [9-12], it was not surprising that the DigitalGlobe image of our study 
area rendered very close observer agreement on both the location and area occupied by the large walrus aggregation present (Figure 4, [31]). Monitoring a walrus haulout with commercial high-resolution imagery, such as that collected by the DigitalGlobe satellites (currently Geoeye-1 and WorldView-1, 2, and 3), requires prearranged scheduling to ensure data collections. DigitalGlobe will also soon deploy "WorldView Legion", a constellation of six satellites (first launch planned for 2021) that will be capable of imaging most places in the world multiple times a day, and Planet Labs is now operating the SkySat constellation of 21 satellites capable of imaging targeted sites with $0.5 \mathrm{~m}$ resolution imagery collected up to 7 times daily [20].

In comparison, Planet Labs operationally collects and archives imagery worldwide every day with its PlanetScope constellation, and Sentinel-2 does the same every 2-3 days at Arctic latitudes, so prearranged acquisitions are not necessary and the broad swath width of these imagery types better enables detection of walrus aggregations that may sometimes move several kilometers within a haulout area. We found that both PlanetScope and Sentinel-2 imagery yielded reasonable agreement among observers on the location and area occupied by walruses (Figure 4). Although PlanetScope images have higher resolution $(4 \mathrm{~m})$ than Sentinel-2 $(10 \mathrm{~m})$, the latter's superior radiometric quality seemed to help compensate its coarser spatial resolution. For a retrospective study like this one aimed at detecting and delineating walrus aggregations, the combined efficacy of PlanetScope's daily archive and Sentinel-2's public archive provided an informative time series of optical imagery, but it was often compromised by periods of persistent cloud cover.

Landsat imagery yielded considerable disagreement among observers in estimating the area occupied by walruses. In 2 of 9 Landsat images classified as having walruses present, observers delineated walrus aggregations at dissimilar locations, resulting in nearzero 3-way overlap among digitized areas (Figure 4). The discrepancies apparently arose in images that had discolorations along the beach, which some observers interpreted to be walruses while others considered the coloration to reflect previous walrus occupancy. This ambiguity of observer interpretation, combined with the sensor's coarse spatial resolution, long revisit interval, and more than two-week latency between image collection and availability (which was generally one day or less for all other imagery sources), indicates Landsat imagery to have limited value for walrus monitoring.

\subsection{SAR Imagery}

Walrus aggregations at the Point Lay haulout produced unambiguous radar backscatter signatures that yielded unanimous detection agreement and high spatial agreement among observers, except for the 40-m resolution Sentinel-1 EW imagery (Figure 2). Adult Pacific walruses are $2.3-3.6 \mathrm{~m}$ in length and beneath their $\sim 2 \mathrm{~cm}$ thick skin they have a 2-6 cm thick blubber layer comprised mostly of lipids [2]. When gathered at coastal haulouts, Pacific walruses crowd together forming a near continuous mat of irregularly arranged biomass 1-2 $\mathrm{m}$ thick that extends over hundreds to tens of thousands of square meters [31]. We found that walrus aggregations produced strong backscatter when imaged with either C-band (Sentinel-1) or X-band (TerraSAR-X) radar, and irrespective of co- (VV, $\mathrm{HH}$ ) or cross-polarization $(\mathrm{VH})$. It is important to note, however, that the fine-grained beach sediments and negligible terrain at the Point Lay haulout provided ideal conditions for minimizing radar returns that might have otherwise been confused for walruses (Figure 1).

Deviations between the estimated area occupied by walruses determined from Sentinel-1 imagery and that of matched UAS surveys were almost always greater than zero (Figure 3). The differences were typically greater in magnitude than those between pairs of nearcontemporary UAS surveys (Figure 3), and the positive bias was persistent across all three observers and contrasts with the positive and negative pattern of deviations among optical imagery matched to UAS surveys (Figure 3). The prevalence of the Sentinel-1 bias suggests one or more factors had consistently contributed to observers inflating the peripheries of walrus aggregations. One factor may stem from the multi-look processing that is applied during SAR image synthesis, which tends to blur edges [36]. The positive bias might 
have been tempered had observers applied a more conservative backscatter threshold for discriminating the edges of aggregations. Also, visually delineating edges becomes more ambiguous as pixel size increases, which likely added to the high observer variability among the Sentinel-1 EW interpretations (Figure 2).

The most precise SAR imagery type for determining the location and areal size of walrus aggregations was the $\sim 1-\mathrm{m}$ resolution staring spotlight mode from TerraSAR-X, which yielded high observer agreements (Table 1 and Figure 4); however, even when operating in the lower-resolution $(3.5 \mathrm{~m})$ stripmap mode, TerraSAR-X produced unambiguous detections of walruses with notable spatial agreement among observers. Compared to the constrained footprint of staring spotlight $(4.6-7.5 \mathrm{~km} \times 2.5-4.6 \mathrm{~km})$, stripmap mode is more capable of imaging larger study sites in a single pass because it collects data over a broader swath (30 $\mathrm{km}$ wide with single polarization).

For monitoring at the Point Lay haulout, we found Sentinel-1 IW to be compromised by long revisit intervals, and Sentinel-1 EW to be compromised by low spatial resolution. Sentinel-1 is presently dedicated to collecting and archiving SAR imagery globally, prioritizing IW mode over land areas and EW mode over oceans [37]. Each of the two Sentinel-1 satellites has a revisit interval of 12 days for the IW mode, however, because the 2 satellites operate in complimentary orbits, their theoretical combined revisit rate is 6 days at the equator and more frequently with increasing latitude. Nevertheless, we only realized a combined $~ 10$-day median revisit rate for the IW mode at our study area (Table 1). It appeared that scheduling nuances for IW and EW acquisitions may have influenced what mode was prioritized for our coastal study site, and the site was unfortunately located at an extreme edge of IW's acquisition grid (data frames along orbital paths), which caused missed opportunities for data collections that would have otherwise yielded a higher revisit rate.

There are several other existing and expanding SAR satellite missions that significantly increase potential revisit rates worldwide. While we acquired only a sample of TerraSAR-X imagery to assess the backscatter of walrus aggregations with a higher resolution X-band instrument, operationally, TerraSAR-X is capable of collecting stripmap imagery of any locale in the Arctic with revisit rates as often as 1-3 days. Furthermore, several other SAR missions have launched multi-satellite constellations capable of imaging high-latitude areas every day, or potentially multiple times a day. In 2019, Canada launched the RADARSAT Constellation [38] comprised of three C-band SAR instruments. RADARSAT data are freely available to approved Canadian users, and possibly to approved international users in the future. Italy's COSMO-SkyMed [39] is a 4-satellite X-band SAR constellation that is currently being upgraded with second generation instruments. Among several modes of operation, COSMO-SkyMed has a $3 \mathrm{~m}$ resolution stripmap product that may be wellsuited for walrus haulout monitoring. Finland's ICEYE [40] is an X-band SAR constellation presently comprised of 10 satellites with plans to launch 8 more in 2022. ICEYE also has a 3-m resolution stripmap mode. In the United States, two commercial SAR companies have recently been established: Capella Space [41] and Umbra Labs Inc. [42]. Capella has launched three X-band SAR satellites with plans to launch four more by late 2021, and Umbra may begin launching its X-band constellation in late 2021. Both Capella and Umbra are designed to acquire high-resolution imagery ( 1-m and finer), and similar to TerraSAR- $X$, both have developed automated interfaces to give customers the ability to schedule data acquisitions themselves on-demand. Collectively, the many existing and emerging sources of SAR imagery suggest that daily or near-daily all-weather monitoring of walrus haulouts may soon be attainable, given advanced scheduling arrangements.

\subsection{Future Research}

Automated algorithms for detecting and delineating walrus aggregations might provide faster and more objective ways to implement broad-scale haulout monitoring than the manual interpretation methods used in this study. Automated walrus detection based on spectral and change detection algorithms have been explored with high-resolution 
imagery [12]. The multiple bands of a multispectral sensor like DigitalGlobe's lend rigor to development of automated detection algorithms. Assessments of lower resolution and less spectrally diverse optical imagery like PlanetScope and Sentinel-2 also warrant a review to ascertain if algorithms could provide reliable and repeatable methods for haulout monitoring objectives. Similarly, the high contrast of walrus aggregations in Cband and X-band SAR imagery relative to non-occupied areas at Point Lay suggests that automated algorithms might offer a repeatable and reliable alternative (or complement) to manual interpretation.

Compared to other haulout sites across the Pacific walrus range [6], the local topography at Point Lay is exceptionally flat and comprised of relatively uniform fine-grained sandy sediments, lending to ideal conditions for minimizing SAR backscatter from nonoccupied areas. In contrast, some of the other large and regularly used walrus haulouts abut bluffs and cliffs, and some beaches have variable sediment sizes including large cobbles or boulders. Such features would likely add several complications to the interpretation of SAR imagery and possibly compromise the ability to detect and discriminate walrus aggregations from non-occupied areas. At haulouts next to cliffs or bluffs, walruses could be rendered undetectable if they occurred within 'shadows' cast by oblique radar look angles. On the other hand, for SAR look angles facing into cliffs, double-bounced backscatter could produce confounding spatial anomalies, while rocky beaches could return backscatter sufficient to make walrus discrimination entirely ambiguous. Research is needed to evaluate SAR at haulouts with different types of terrain and substrates. Acquiring reference images of vacant beaches may provide baselines for detecting backscatter changes (including interferometry) produced by walrus occupancy. Field observations of walrus aggregations collected at the same time as SAR acquisitions are necessary to robustly evaluate methods designed to discriminate walruses at topographically complex haulout areas.

The positive bias of aggregation areas created from visual interpretation of Sentinel-1 imagery, as well as the variability among observers, was largely driven by differences in deciding how many pixels to include in an aggregation and not by disagreements in the presence or general locations of aggregations. Visual interpretations of the Sentinel-1 imagery could be improved through simultaneous collections of aerial imagery to quantify more precise backscatter thresholds for the delineation of aggregation peripheries.

In this study, we estimated the area occupied by walruses by outlining walrus aggregations apparent in satellite imagery. Knowledge of the occurrence and location of these aggregations can help managers mitigate potential disturbances in near-real time; yet, managers also need estimates of the number of walruses present on shore. We could not address abundance directly in this study because none of the satellite imagery types that we evaluated enabled counting individual walruses when they were gathered closely together onshore, and we could not address abundance indirectly because the densities of walruses when hauled out on shore are known to vary. Aggregation densities at the Point Lay haulout averaged 0.87 walruses per square meter (sd 0.17, n 26), and ranged from 0.67 to 1.5 [25]. If we were to estimate walrus abundance based on the product of area occupied and the published densities (mean and variance), confidence intervals would likely be broad. If it were possible to estimate density with minimal variance from satellite imagery, then walrus abundance could be more precisely estimated using satellite imagery alone. Further research is needed to assess whether high resolution $(<1 \mathrm{~m})$ optical or SAR images contain sufficient information to accurately estimate walrus densities across fine spatial scales. Given that haulouts can shift in size over the course of just hours, field validation data (such as UAS survey imagery) collected coincident with prearranged satellite acquisitions would be required to robustly quantify relationships between the in-situ densities and those estimated with satellite data.

\section{Conclusions}

Both optical and radar satellite imagery with resolutions $\leq 10 \mathrm{~m}$ were useful in detecting the presence, areal size, and geographic position of walrus aggregations at a 
terrestrial haulout near Point Lay, Alaska. Results of this study suggest that satellite reconnaissance could expand haulout monitoring tools in a cost-effective manner relative to on-site options. Satellite imagery clearly revealed large walrus aggregations and allowed for quantification of the area occupied by those aggregations. Although large aggregations were evident in satellite imagery at the Point Lay study site, further research is needed to evaluate the capability of satellite imagery to distinguish walrus aggregations across the Pacific walrus range, including sites with more complex beach substrates and local topography. Estimating the actual number of walruses present at a haulout might be possible using very high-resolution satellite imagery, but only after calibration studies with simultaneously collected aerial imagery are successful.

Supplementary Materials: The following is available online at https:/ /www.mdpi.com/article/10 $.3390 / \mathrm{rs} 13214266 / \mathrm{s} 1$, Table S1: Tabulation of satellite images matched to within $24 \mathrm{~h}$ of UAS survey.

Author Contributions: Conceptualization, A.S.F.; methodology, A.S.F. and D.C.D.; validation, A.S.F. and D.C.D.; formal analysis, A.S.F. and D.C.D.; investigation, A.S.F. and D.C.D.; data curation, A.S.F.; writing — original draft preparation, A.S.F.; writing—review and editing, A.S.F. and D.C.D.; visualization, A.S.F.; funding acquisition, D.C.D. All authors have read and agreed to the published version of the manuscript.

Funding: This research was funded by the U.S. Geological Survey.

Institutional Review Board Statement: The study was conducted according to the fundamental science practices of the USGS and received bureau approval (information product documentation system number IP-131033 on 13 September 2021).

Informed Consent Statement: This study was conducted with informed consent of the Eskimo Walrus Commission, an Alaska Native co-management group that represents Alaskan coastal communities that rely on walruses.

Data Availability Statement: All data derived and summarized by this study are available online. Fischbach, A.S., Douglas, D.C., Monette, C.J. 2020, Walrus haulout outlines apparent from satellite imagery near Point Lay Alaska, autumn 2018, 2019, and 2020: U.S. Geological Survey data release, https:/ / doi.org/10.5066/P9S2UL7N (accessed on 20 October 2021).

Acknowledgments: We are grateful to the Eskimo Walrus Commission for consulting on the study design. Collin Monette served at the third visual interpreter and provided insightful adjustments to optical imagery visualization as well as technical reviews of manuscript drafts. Timm Nawrocki and Jessica Walker provided guidance on use of Google Earth Engine for access to Landsat and Sentinel data. Ursula Marschalk provided guidance on TeraSAR-X imagery collection. Chelsea Piccone provided guidance on PlanetLabs PlanetScope imagery. Achim Roth, Christopher Noyles, Tanya Harrison, and Ursula Marschalk reviewed drafts of the manuscript. Klaus Albrecht of the ANUVA $\mathrm{GmbH}$ landscape planning firm facilitated acquisition of the TerraSAR-X imagery. Observations of walrus occurrence along the Chukchi Sea coast of Alaska were provided through the community of Point Lay by Marie Tracey and Warren Harding-Lampe, and through NOAA's Aerial Surveys of Arctic Marine Mammals program. The European Space Agency and the German Aerospace Agency (DLR) kindly granted access to TerraSAR-X imagery archive and the DLR granted acquisition of new imagery for our science application. Any use of trade, firm, or product names is for descriptive purposes only and does not imply endorsement by the U.S. Government.

Conflicts of Interest: The authors declare no conflict of interest.

\section{References}

1. Udevitz, M.S.; Taylor, R.L.; Garlich-Miller, J.L.; Quakenbush, L.T.; Snyder, J.A. Potential population-level effects of increased haulout-related mortality of Pacific walrus calves. Polar. Biol. 2013, 36, 291-298. [CrossRef]

2. Garlich-Miller, J.; MacCracken, J.G.; Snyder, J.; Meehan, R.; Myers, M.; Wilder, J.M.; Lance, E.; Matz, A. Status Review of the Pacific Walrus (Odobenus Rosmarus Divergens); U.S. Department of the Interior, U.S. Fish and Wildlife Service: Washington, DC, USA, $2011 ; 155 p$.

3. Citta, J.J.; Quakenbush, L.T.; Taras, B.D. Estimation of calf: Cow ratios of Pacific walruses for use in population modeling and monitoring. Mar. Mammal. Sci. 2014, 30, 20-43. [CrossRef] 
4. Speckman, S.G.; Chernook, V.I.; Burn, D.M.; Udevitz, M.S.; Kochnev, A.A.; Vasilev, A.; Jay, C.V.; Lisovsky, A.; Fischbach, A.S.; Benter, R.B. Results and evaluation of a survey to estimate Pacific walrus population size. Mar. Mammal. Sci. 2011, 27, 514-553. [CrossRef]

5. Battaile, B.C.; Jay, C.V. Walrus Haulout Photographs Near Pt. Lay Alaska, September 2014; U.S. Geological Survey Data Release; U.S. Geological Survey: Anchorage, AK, USA, 2021. [CrossRef]

6. Fischbach, A.S.; Kochnev, A.A.; Garlich-Miller, J.L.; Jay, C.V. Pacific Walrus Coastal Haulout Database, 1852-2016-Background Report; U.S. Geological Survey Open-File Report 2016-1108; U.S. Geological Survey: Anchorage, AK, USA, 2016; 27p. [CrossRef]

7. Onarheim, I.H.; Eldevik, T.; Smedsrud, L.H.; Stroeve, J.C. Seasonal and regional manifestation of Arctic sea ice loss. J. Clim. 2018, 31, 4917-4932. [CrossRef]

8. Jay, C.V.; Fischbach, A.S.; Kochnev, A.A. Walrus areas of use in the Chukchi Sea during sparse sea ice cover. Mar. Ecol. Prog. Ser. 2012, 468, 1-13. [CrossRef]

9. Burn, D.M.; Cody, M.B. Use of Satellite Imagery to Estimate Walrus Abundance at Round Island, Alaska. In Proceedings of the 16th Biennial Conference on the Biology of Marine Mammals, San Diego, CA, USA, 12-16 December 2005.

10. Semenova, V.S.; Knizhnikov, A.Y.; Boltunov, A.N.; Evtushenko, N.V. Study of Atlantic walruses in the Barents Sea using space technologies. Earth Space 2011, 10, 89-90.

11. Platonov, N.G.; Mordvintsev, I.N.; Rozhnov, V.V. The possibility of using high resolution satellite images for detection of marine mammals. Biol. Bull. 2013, 40, 197-205. [CrossRef]

12. Zinglersen, K.B.; Garde, E.; Langley, K.; Mätzler, E. RemoteID: Identification of Atlantic Walrus at Haul Out Sites in Greenland Using High-Resolution Satellite Images; Technical Report No. 111; Greenland Institute of Natural Resources: Nuuk, Greenland, 2019; 62p, ISBN 87-91214-89-0.

13. LaRue, M.A.; Rotella, J.J.; Garrott, R.A.; Siniff, D.B.; Ainley, D.G.; Stauffer, G.E.; Porter, C.C.; Morin, P.J. Satellite imagery can be used to detect variation in abundance of Weddell seals (Leptonychotes weddellii) in Erebus Bay, Antarctica. Polar Biol. 2011, 34, 1727-1737. [CrossRef]

14. McMahon, C.R.; Howe, H.; van den Hoff, J.; Alderman, R.; Brolsma, H.; Hindell, M.A. Satellites, the all-seeing eyes in the sky: Counting elephant seals from space. PLoS ONE 2014, 9, e92613. [CrossRef] [PubMed]

15. Moxley, J.H.; Bogomolni, A.; Hammill, M.O.; Moore, K.M.T.; Polito, M.J.; Sette, L.; Sharp, W.B.; Waring, G.T.; Gilbert, J.R.; Halpin, P.N.; et al. Google haul out: Earth observation imagery and digital aerial surveys in coastal wildlife management and abundance estimation. BioScience 2017, 67, 760-768. [CrossRef] [PubMed]

16. Landsat Missions. Available online: https://usgs.gov/landsat (accessed on 29 July 2021).

17. Sentinel Online. Available online: https://sentinel.esa.int (accessed on 29 July 2021).

18. Discover Digital Globe. Available online: https:/ / discover.digitalglobe.com (accessed on 29 July 2021).

19. Airbus. Available online: https:/ / www.intelligence-airbusds.com (accessed on 29 July 2021).

20. Planet. Available online: https:/ / www.planet.com (accessed on 29 July 2021).

21. CubeSat. Available online: https:/ / www.cubesat.org (accessed on 29 July 2021).

22. Poghosyan, A.; Golkar, A. CubeSat evolution: Analyzing CubeSat capabilities for conducting science missions. Prog. Aerosp. Sci. 2017, 88, 59-83. [CrossRef]

23. Hand, E. Startup liftoff. Science 2015, 348, 172-177. [CrossRef] [PubMed]

24. McCabe, M.F.; Aragon, B.; Houborg, R.; Mascaro, J. CubeSats in hydrology: Ultrahigh-resolution insights into vegetation dynamics and terrestrial evaporation. Water Resour. Res. 2017, 53, 10017-10024. [CrossRef]

25. Fischbach, A.S.; Jay, C.V.; Monette, C.J.; Adams, J.D. Walrus Haulout Outlines and Count Data Apparent from Aerial Survey Images Collected Near Point Lay Alaska, Autumn 2018 and 2019; U.S. Geological Survey Data Release; U.S. Geological Survey: Anchorage, AK, USA, 2021. [CrossRef]

26. Eskimo Walrus Commission. Available online: https:/ / eskimowalruscommission.org (accessed on 29 July 2021).

27. Eineder, M.; Fritz, T.; Mittermayer, J.; Roth, A.; Boerner, E.; Breit, H.; Braeutigam, T.; Kraus, T. TerraSAR-X Ground Segment; Basic Product Specification Document No. TX-GS-DD-3302, Issue 1.9; German Aerospace Center (DLR), 2013; 126p. Available online: https: / / sss.terrasar-x.dlr.de/docs/TX-GS-DD-3302.pdf (accessed on 29 July 2021).

28. Google Earth Engine. Available online: https:/ / earthengine.google.com (accessed on 29 July 2021).

29. Lisle, R.J. Google Earth: A new geological resource. Geol. Today 2006, 22, 29-32. [CrossRef]

30. Haklay, M.; Weber, P. Openstreetmap: User-generated street maps. IEEE Pervasive Comput. 2008, 7, 12-18. [CrossRef]

31. Fischbach, A.S.; Douglas, D.C.; Monette, C.J. Walrus Haulout Outlines Apparent from Satellite Imagery Near Point Lay Alaska, Autumn 2018, 2019 and 2020; U.S. Geological Survey data release; U.S. Geological Survey: Anchorage, AK, USA, 2020. [CrossRef]

32. Battaile, B.C.; Jay, C.V.; Udevitz, M.S.; Fischbach, A.S. Evaluation of a method using survey counts and tag data to estimate the number of Pacific walruses (Odobenus rosmarus divergens) using a coastal haulout in northwestern Alaska. Polar Biol. 2017, 40, 1359-1369. [CrossRef]

33. National Centers for Environmental Information, Climate Data Online. Available online: https://www.ncdc.noaa.gov/cdo-web (accessed on 20 June 2021).

34. Global Monitoring Laboratory, Solar Calculator. Available online: https:/ / gml.noaa.gov (accessed on 20 June 2021). 
35. Kochnev, A.A. The haulout of Pacific walruses (Odobenus rosmarus divergens) on Cape Serdtse-Kamen, the Chukchi Sea. In Proceedings of the Marine Mammals of the Holarctic, Collection of Scientific Papers after the Sixth International Conference, Kaliningrad, Russia, 11-15 October 2010; pp. 281-285. Available online: https:/ /www.researchgate.net/profile/Anatoly-Kochnev/ publication/317256277_The_haulout_of_Pacific_walruses_Odobenus_rosmarus_divergens_on_Cape_Serdtse-Kamen_the_ Chukchi_Sea/links/592e79b5a6fdcc89e75ca081/The-haulout-of-Pacific-walruses-Odobenus-rosmarus-divergens-on-CapeSerdtse-Kamen-the-Chukchi-Sea.pdf (accessed on 29 July 2021).

36. Moreira, A.; Prats-Iraola, P.; Younis, M.; Krieger, G.; Hajnsek, I.; Papathanassiou, K.P. A tutorial on synthetic aperture radar. IEEE Geosci. Remote Sens. Mag. 2013, 1, 6-43. [CrossRef]

37. Copernicus Space Component Mission Management Team. Sentinel High Level Operations Plan; COPE-S1OP-EOPG-PL-15-0020; European Space Agency, 2019; 78p. Available online: https://sentinels.copernicus.eu/documents/247904/685154/Sentinel_ High_Level_Operations_Plan (accessed on 29 July 2021).

38. RADARSAT Constellation Mission. Available online: https://www.asc-csa.gc.ca/eng/satellites/radarsat (accessed on 20 June 2021).

39. COSMO-SkyMed. Available online: https://www.asi.it/en/earth-science/cosmo-skymed (accessed on 20 June 2021).

40. IceEye. Available online: https:/ / www.iceye.com (accessed on 29 July 2021).

41. Capella Space. Available online: https:/ / www.capellaspace.com (accessed on 29 July 2021).

42. Umbra. Available online: https:/ / umbra.space (accessed on 29 July 2021). 